\title{
Inobvious complications of hypoglycaemia
}

\section{ABSTRACT}

Tight blood glucose control reduces long-term complications in both type 1 and type 2 diabetes, however increases the risk of hypoglycaemia. The article describes rare acute complications of severe hypoglycaemia - acute pulmonary oedema, stress cardiomyopathy (takotsubo cardiomyopathy) and cardiac arrhythmias including bradycardia or ventricular arrhythmias related probably to QT prolongation. All mentioned acute complications can be life-threatening and lead to sudden death even in young subjects. In some situations they may be misdiagnosed or overlooked. (Clin Diabetol 2017; 6, 4: 147-150)

Key words: pulmonary oedema, stress cardiomyopathy, cardiac arrhythmias, QT prolongation, hypoglycaemia

\section{Introduction}

Hypoglycaemia is an extremely common complication of the treatment of diabetes. In addition to the typical symptoms and complications, it can also lead to disorders that are rarely taken into account. These include pulmonary oedema, stress cardiomyopathy and cardiac arrhythmias, particularly bradycardia and ventricular arrhythmias possibly associated with QT prolongation.

\section{Address for correspondence:}

prof. dr hab. n. med. Liliana Majkowska

Klinika Diabetologii i Chorób Wewnętrznych

Pomorski Uniwersytet Medyczny

ul. Siedlecka 2, 72-010 Police

Phone: +48914253858

e-mail: majkaend@pum.edu.pl

Translation: lek. Małgorzata Kamińska

Clinical Diabetology 2017, 6, 4, 147-150

DOI: $10.5603 /$ DK.2017.0025

Received: 07.10.2017

Accepted: 08.10.2017

\section{Pulmonary oedema}

In the 1930s and 1950s pulmonary oedema was described as a severe and dangerous complication of insulin shock therapy that has been used in people with schizophrenia [1, 2]. In one of the observations of this period, pulmonary oedema occurred in 3 out of 26 patients, i.e. in $11.5 \%$ of patients [1]. Analysis of the deaths of patients treated with insulin shocks showed that pulmonary oedema was the second leading cause of death, after irreversible coma. Complications were reported in 7 out of 44 cases of death (i.e. in 15.9\%), with the majority of patients being young [2].

Currently, pulmonary oedema is a completely forgotten complication of severe hypoglycaemia and it appears that it is not considered as a result of glucose-lowering treatment in diabetic patients. In the available literature, single cases of pulmonary oedema in patients with drug-induced hypoglycaemia can be found. One of the first descriptions concerned 40-year-old insulin-treated patient and 42-year-old insulin-treated patient being alcohol abused $[3,4]$. Other reports described patients with type 1 diabetes - a 19-year-old woman with severe insulin-induced hypoglycaemia, a 16-year-old girl with hypoglycaemic coma who probably intentionally overdosed insulin in order to commit suicide and a 23-year-old men with a loss of consciousness after insulin injection [5-7]. In all these patients, clinical and radiological features of pulmonary oedema appeared during in-hospital follow-up, despite good glycaemic control. Because the patients were young, without cardiovascular burden, the authors suggested a neurogenic background of pulmonary oedema and attributed it to an excessive amount of catecholamines released during hypoglycaemia. None of the described patients underwent cardiac imaging. Rapid hypoglycaemia-induced release of catecholamines would lead to narrowing of the pulmonary vessels, platelet aggregation, formation of microemboli in the pulmonary 
circulation and, consequently, to sudden increase in pulmonary vascular pressure and pulmonary oedema [8]. Hyperinsulinaemia and hypoglycaemia are thought to be directly involved in the formation of transudates by increasing vascular permeability $[9,10]$.

Neurogenic pulmonary oedema was also suggested in a 49-year-old patient with unknown disease history, alcohol abuse and traumatic brain injury without significant new changes in cerebral computer tomography [11]. Initially, a typical neurogenic oedema associated with head injury was suspected. However, iatrogenic hypoglycaemia of $19 \mathrm{mg} / \mathrm{dL}$ was observed at the time pulmonary oedema occurred. It was caused by shortacting insulin administered subcutaneously because of previous hyperglycaemia (388 $\mathrm{mg} / \mathrm{dL}$ ) of unclear aetiology. In the ECG, negative T waves appeared in the precordial leads and were observed for several consecutive days. Cardiac ultrasound showed a reduced ejection fraction (55\%) without structural changes in the heart.

A case report published in 2013 shed slightly different light on the potential cause of pulmonary oedema in patients with hypoglycaemia [12]. Severe hypoglycaemia $(18 \mathrm{mg} / \mathrm{dL}$ ) and unconsciousness occurred in a 78-year-old man with type 2 diabetes after taking unidentified hypoglycaemic drugs. Despite resolution of hypoglycaemia, the patient developed pulmonary oedema and ECG changes in a form of ST segment elevation appeared in V2-V3 leads, which were suggestive of ST segment elevation myocardial infarction (STEMI). Urgent coronary angiography did not show coronary artery occlusion. Ultrasound examination and ventriculography showed changes characteristic of stress cardiomyopathy.

\section{Stress cardiomyopathy (broken-heart syndrome, takotsubo cardiomyopathy)}

Hypoglycaemia may lead to left ventricular dysfunction involving mainly the apical region, as is the case of stress cardiomyopathy which is caused by severe emotional stress despite the absence of atherosclerotic lesions in coronary arteries. Myocardial dysfunction in the apical region is usually accompanied by hypercontraction of the basal segment. Because of the left ventricle's appearance in ventriculography, the syndrome described for the first time by Satoh et al. [13] has been termed apical ballooning syndrome or takotsubo syndrome (takotsubo is a fishing pot used for trapping octopuses in Japan) [13]. Clinical manifestation may include syncope, cardiogenic shock, pulmonary oedema retrosternal pain, and palpitations. The most frequent electrographic features are ST elevation, T-wave reversal, and abnormal Q-wave, that is changes suggestive of acute myocardial infarction. These changes may be accompanied by short-term and slight increase in troponin and CK-MB levels. There are no lesions in coronary arteries in coronary angiography. Clinical improvement is rapid. It is believed that these symptoms are caused by an excess of catecholamines that lead to "stunning" of the myocardium or multivessel coronary spasm. This syndrome is mainly seen in postmenopausal women and is triggered by severe emotional stress.

There are several reports on hypoglycaemia-induced takotsubo syndrome available in the literature. One of them was a 69-year-old non-diabetic woman admitted to hospital due to loss of consciousness caused by hypoglycaemia ( $32 \mathrm{mg} / \mathrm{dL}$ at admission) of unknown cause in whom tachycardia, gallop rhythm, and pulmonary haemostasis were observed [14]. The ejection fraction in cardiac ultrasound examination was $16 \%$; ventriculography showed ballooning of the apex, which is typical for the takotsubo syndrome; coronary angiography showed non-obstructive fundings. Significant improvement was observed after a few days (ejection fraction increased to $45 \%$ ). Hypoglycaemia-induced takotsubo cardiomyopathy was also described in a 17-year-old woman with anorexia nervosa [15]. The patient became unconscious due to hypoglycaemia (20 $\mathrm{mg} / \mathrm{dL}$ ). After recovery from hypoglycaemia, the patient did not report any complaints. One day later, despite the absence of clinical symptoms, ECG showed tachycardia and negative T waves in leads II, III, aVF, V3-V6. Moreover increased levels of CK and CK-MB were observed and cardiac ultrasound image was typical for apical ballooning syndrome, with ejection fraction of $56 \%$. Impaired uptake was observed in the apical region on cardiac scintigraphy. Cardiac ultrasound image became normal after 10 days, while ECG changes were maintained for 4 months. In two other young women with anorexia nervosa ( 25 and 32 years old), described in the same paper, T-wave and ST-segment changes suggestive of myocardial ischaemia with a slight increase in CK-MB were found after episodes of hypoglycaemia. No abnormalities were found in the ultrasound and myocardial scintigraphy, but the imaging studies were performed after a long time following the hypoglycaemic episode (in one patient after 4 and 9 days, and after one month in the other). The authors suggest two possibilities: these patients had atypical takotsubo syndrome, or changes characteristic of this syndrome were lacking because ultrasound examinations were performed to late [15].

Only one report on the presence of takotsubo syndrome in diabetic patient with hypoglycaemia is available in the literature [12]. This is above-mentioned case of 78-year-old man with type 2 diabetes, pulmonary oedema, ECG features typical of STEMI and normal 
coronary arteries in echocardiography. Left ventricular scans in echocardiography and ventriculography were characteristic of the apical ballooning syndrome. Echocardiographic examination performed a few days later showed improved performance of the left ventricle and the ejection fraction was $77 \%$. In the case described above, the left ventricular dysfunction characteristic of the takotsubo syndrome led to pulmonary oedema.

It cannot be ruled out that hypoglycaemia-induced pulmonary oedema may be caused by this mechanism. It can also be assumed that some cases of painless myocardial infarction observed in patients with hypoglycaemia, which are diagnosed based on ECG changes and increased cardiac enzyme levels, but not confirmed in coronary angiography, may be takotsubo syndrome [16].

\section{Cardiac arrhythmias}

Technological progress in continuous glucose monitoring (CGM) and ambulatory ECG registration (Holter) has allowed for identification of many hypoglycaemiainduced cardiac arrhythmias, even in patients without any clinical symptoms of hypoglycaemia [17-20].

In a recently published study on young patients with type 1 diabetes, CGM revealed that $6.6 \%$ of the recording time was designated as hypoglycaemia, with median duration of nocturnal hypoglycaemia of about 60 minutes and median duration of daytime hypoglycaemia of about 44 minutes [17]. Only $24 \%$ of nocturnal and $51 \%$ of daytime hypoglycaemia episodes were symptomatic. Bradycardia was the most common cardiac arrhythmia. Nocturnal hypoglycaemia increased the risk of bradycardia by more than 6 times, while no risk change was observed at daytime. Other ECG changes included prolongation of QT interval and T wave flattening. Other authors also reported QT prolongation and bradycardia during hypoglycaemia [18]. Night-time hypoglycaemia in patients with type 1 diabetes aged 20-50 years of age was associated with significant QT interval prolongation, bradycardia $<40$ / $/ \mathrm{min}$, and ventricular arrhythmias. It should be noted that hypoglycaemia was frequent in this group of patients and accounted for about $26 \%$ of all records, with the glucose level in most cases less than $40 \mathrm{mg} / \mathrm{dL}$ $(2.2 \mathrm{mmol} / \mathrm{L})$ [18]. As the prolongation of QT interval may induce torsade de pointes, the authors suggest a direct relationship between observed cardiac arrhythmias and "dead in bed" syndrome.

Hypoglycaemia-induced heart rhythm disorders are considered to be the result of a considerable catecholamine hypersecretion, which directly and indirectly affects the repolarization processes by lowering the concentration of potassium ions in the extracellular fluid
[19]. It appears that in patients with type 1 diabetes, the presence of autonomic neuropathy is not related to QT prolongation in hypoglycaemia. This phenomenon occurs both in patients with and without autonomic neuropathy [19]. Hypoglycaemia-induced prolongation of QT interval may be observed also in non-diabetic patients [20]. The phenomenon was accompanied by more than 10-fold increase in catecholamine levels and transient hypokalaemia.

Disorders including QT prolongation and ventricular arrhythmias related to hypoglycaemia were also reported in patients with type 2 diabetes [21, 22]. This problem affects not only patients treated with insulin but also those receiving sulfonylureas [22, 23]. Hypoglycaemia-induced heart rhythm disorders are particularly dangerous in patients with cardiovascular diseases in whom catecholamine hypersecretion may increase oxygen requirement and the exacerbation of ischaemia. Ventricular arrhythmias in patients with type 2 diabetes and cardiovascular disease may be above 30 times more frequent than in patients without hypoglycaemia [22]. It is extremely important that in the cited study only $39 \%$ of patients noted hypoglycaemic symptoms during the day, and even fewer $-11 \%-$ reported nocturnal hypoglycaemia. Another study in patients with type 2 diabetes and concomitant cardiovascular disease showed that night-time hypoglycaemia increased the risk of bradycardia by more than 8 times, with a 3-fold increase in ventricular arrhythmias, and almost 4-fold increase in supraventricular arrhythmias [24]. During the day, hypoglycaemia increased the risk of ventricular arrhythmia by about $1 / 3$, but bradycardia or increased frequency of supraventricular arrhythmias were not observed. The special effect of nocturnal hypoglycaemia is explained by increased parasympathetic tone and lower activity of sympathetic system compared to daytime hours [25].

\section{Summary}

The above-mentioned complications of hypoglycaemia may be life-threatening and lead to sudden death in many diabetic patients even in young age. However, these complications are rarely taken into account and may be misdiagnosed or overlooked.

\section{REFERENCES}

1. Nielsen JM, Ingham S, Hagen KV. Pulmonary edema and embolism as complication of insulin shock in treatment of schizophrenia. JAMA. 1938; 111(27): 2455-2458, doi: 10.1001/ /jama.1938.02790530009004.

2. Maclay WS. Death due to treatment. Proc R Soc Med. 1953; 46(1): 13-20, indexed in Pubmed: 13027286.

3. Weber FP, Blum K. Acute pulmonary oedema with hypoglycemic coma: an example of acute pulmonary oedema of nervous origin. 
J Neurol Psychiatry. 1942; 5(1-2): 37-39, doi: 10.1136/jnnp.5.12.37, indexed in Pubmed: 21611401.

4. Baruh S, Sherman L. Hypoglycemia, a cause of pulmonary edema. Progressive, fatal pulmonary edema complicating hypoglycemia induced by alcohol and insulin. J Natl Med Assoc. 1975; 67(3): 200-204, indexed in Pubmed: 1142455.

5. Ortega E, Wagner A, Caixàs A, et al. Hypoglycemia and pulmonary edema: a forgotten association. Diabetes Care. 2000; 23(7): 1023-1024, doi: 10.2337/diacare.23.7.1023, indexed in Pubmed: 10895861

6. Uchida $D$, Ohigashi $S$, Hikita $S$, et al. Acute pulmonary edema caused by hypoglycemia due to insulin overdose. Intern Med. 2004; 43(11): 1056-1059, doi: 10.2169/internalmedicine.43.1056, indexed in Pubmed: 15609702.

7. Mishriki YY. Hypoglycemia-induced neurogenic-type pulmonary edema: an underrecognized association. Endocr Pract. 2004; 10(5): 429-431, doi: 10.4158/EP.10.5.429, indexed in Pubmed: 15760791.

8. Arem R, Zoghbi W. Insulin overdose in eight patients: insulin pharmacokinetics and review of the literature. Medicine (Baltimore). 1985; 64(5): 323-332, doi: 10.1097/00005792-19850900000004, indexed in Pubmed: 3897766.

9. Evans DJ, Pritchard-Jones K, Trotman-Dickenson B. Insulin oedema. Postgrad Med J. 1986; 62(729): 665-668, doi: 10.1136/ /pgmj.62.729.665, indexed in Pubmed: 3529068.

10. Hilsted J, Frandsen $\mathrm{H}$, Christensen NJ, et al. Plasma volume changes during hypoglycaemia: the effect of autonomic blockade. Eur J Clin Invest. 1991; 21(1): 22-26, doi: 10.1111/j.1365-2362.1991. tb01353.x, indexed in Pubmed: 1907551.

11. Margulescu AD, Sisu RC, Cinteza M, et al. Noncardiogenic acute pulmonary edema due to severe hypoglycemia - an old but ignored cause. Am J Emerg Med. 2008; 26(7): 839.e3-839.e6, doi: 10.1016/j.ajem.2008.01.037, indexed in Pubmed: 18774061.

12. Yu SH, Su HM, Lin TH, et al. Acute cardiogenic pulmonary edema induced by severe hypoglycemia - a rare case report. Int J Cardiol. 2013; 168(3): e94-e95, doi: 10.1016/j.ijcard.2013.07.122, indexed in Pubmed: 23920060.

13. Satoh $H$, Tateishi $H$, Uhida T. Takotsubo-type cardiomyopathy due to mulitivessel spasm. In: Kodoma K, Haze K, Hon M. ed. Clinical aspects of myocardial injury: from ischemia to heart failure. Kagakuhyouronsya Co, Tokyo 1990: 56-64.

14. Ansari MJ, Prasad A, Pellikka PA, et al. Takotsubo cardiomyopathy caused by hypoglycemia: A unique association with coronary arterial calcification. Int J Cardiol. 2011; 147(2): e21-e23, doi: 10.1016/j.ijcard.2009.01.016, indexed in Pubmed: 19233494.
15. Ohwada R, Hotta M, Kimura H, et al. Ampulla cardiomyopathy after hypoglycemia in three young female patients with anorexia nervosa. Intern Med. 2005; 44(3): 228-233, doi: 10.2169/internalmedicine.44.228, indexed in Pubmed: 15805712.

16. Mahajan VV, Dogra V, Pargal I, et al. Silent myocardial infarction during hypoglycemic coma. Indian J Endocrinol Metab. 2012; 16(1): 139-140, doi: 10.4103/2230-8210.91210, indexed in Pubmed: 22276266.

17. Novodvorsky P, Bernjak A, Chow E, et al. Diurnal Differences in Risk of Cardiac Arrhythmias During Spontaneous Hypoglycemia in Young People With Type 1 Diabetes. Diabetes Care. 2017; 40(5): 655-662, doi: 10.2337/dc16-2177, indexed in Pubmed: 28213374.

18. Gill GV, Woodward A, Casson IF, et al. Cardiac arrhythmia and nocturnal hypoglycaemia in type 1 diabetes - the 'dead in bed' syndrome revisited. Diabetologia. 2009; 52(1): 42-45, doi: 10.1007/s00125-008-1177-7, indexed in Pubmed: 18972096.

19. Heller SR. Abnormalities of the electrocardiogram during hypoglycaemia: the cause of the dead in bed syndrome? Int J Clin Pract Suppl. 2002(129): 27-32, indexed in Pubmed: 12166602.

20. Kacheva S, Karges B, Göller K, et al. QT prolongation caused by insulin-induced hypoglycaemia - An interventional study in 119 individuals. Diabetes Res Clin Pract. 2017; 123: 165-172, doi: 10.1016/j.diabres.2016.11.021, indexed in Pubmed: 28024277.

21. Cha SAh, Yun JS, Lim TS, et al. Baseline-Corrected QT (QTC) Interval Is Associated with Prolongation of QTc during Severe Hypoglycemia in Patients with Type 2 Diabetes Mellitus. Diabetes Metab J. 2016; 40(6): 463-472, doi: 10.4093/dmj.2016.40.6.463, indexed in Pubmed: 27766792.

22. Pistrosch F, Ganz X, Bornstein SR, et al. Risk of and risk factors for hypoglycemia and associated arrhythmias in patients with type 2 diabetes and cardiovascular disease: a cohort study under real-world conditions. Acta Diabetol. 2015; 52(5): 889-895, doi: 10.1007/s00592-015-0727-y, indexed in Pubmed: 25749806.

23. Middleton TL, Wong J, Molyneaux L, et al. Cardiac Effects of Sulfonylurea-Related Hypoglycemia. Diabetes Care. 2017; 40(5): 663-670, doi: 10.2337/dc16-1972, indexed in Pubmed: 28223296.

24. Chow E, Bernjak A, Williams S, et al. Risk of cardiac arrhythmias during hypoglycemia in patients with type 2 diabetes and cardiovascular risk. Diabetes. 2014; 63(5): 1738-1747, doi: 10.2337/ /db13-0468, indexed in Pubmed: 24757202.

25. Clark AL, Best CJ, Fisher SJ. Even silent hypoglycemia induces cardiac arrhythmias. Diabetes. 2014; 63(5): 1457-1459, doi: 10.2337/db14-0108, indexed in Pubmed: 24757198. 